\title{
A CADEIA DE DECISÕES DO SUPREMO TRIBUNAL FEDERAL SOBRE A COMPETÊNCIA PARA JULGAR ATOS DO CONSELHO NACIONAL DE JUSTIÇA: UM ESTUDO RETROSPECTIVO
}

\section{THE SUPREME FEDERAL COURT'S CHAIN OF DECISIONS ON JURISDICTION TO JUDGE ACTS OF THE NATIONAL COUNCIL OF JUSTICE: A RETROSPECTIVE STUDY}

\author{
Janaína Lima Penalva da Silva ${ }^{1}$ \\ Adriene Domingues Costa ${ }^{2}$
}

RESUMO: Este artigo analisa as principais decisões do Supremo Tribunal FederalSTF sobre a competência para julgamento de ações contra o Conselho Nacional de Justiça, no período de 2005 a 2019. O estudo utiliza a metáfora do "romance em cadeia" de Ronald Dworkin para reconstruir a história de julgados sobre a competência originária dos juízes de primeiro grau para julgar atos do CNJ. O estudo demonstra que a "jurisprudência defensiva" que animou o STF no tema está baseada na confusão entre política e princípio. O estudo também evidencia como o posicionamento processual do Supremo Tribunal Federal impactou a autoridade do CNJ, em nível disciplinar e de governança.

\footnotetext{
1 Professora Adjunta da Faculdade de Direito da Universidade de Brasília. Pós-Graduada em Direito e Bioética pela Universidade de Barcelona, Espanha. Bolsista do Programa de Mobilidade de Professores da Fundação Carolina, Universidade de Granada, Espanha (2014/2015). Ex-Diretora Executiva do Departamento de Pesquisas Judiciárias do Conselho Nacional de Justiça (2012/2014) e Ex-Secretária Executiva do Centro de Estudos Judiciários do Conselho da Justiça Federal (2010/2012). Membro da Coordenação do Centro de Estudos em Desigualdade e Discriminação da Universidade de Brasília/UnB. Membro do Fórum Nacional da Saúde/CNJ. Atuação acadêmica nas áreas de metodologia de pesquisa em direito, acesso à justiça, direitos fundamentais sociais, bioética, estudos em gênero e violência contra a mulher. ORCID: https://orcid.org/0000-00025834-7651

${ }^{2}$ Mestre em Administração Pública pelo IDP/EAB e pós-graduada em Direito Empresarial pelo IEC (PUC/MG). Graduou-se na PUC/MG em 1997. Trabalhou de 2002 a 2007 no Ministério Público de Minas Gerais, onde atuou na área de Direitos Coletivos. Chefiou o Gabinete dos Representantes do Ministério Público dos Estados no Conselho Nacional de Justiça - CNJ de 2007 até 2018. $\dot{E}$ chefe de gabinete da Secretaria Nacional de Justiça desde janeiro de 2019, atuando também como Secretária Nacional de Justiça substituta. ORCID
} 
Palavras-chave: Conselho Nacional de Justiça. Supremo Tribunal Federal. Processo constitucional. Integridade do Direito.

ABSTRACT: The article analyzes the main judgments of the Brazilian Supreme Court (STF) about its jurisdiction to adjudicate acts of National Justice Council (CNJ), from 2005 to 2019. The study uses Ronald Dworkin's "chain romance" metaphor to reconstruct the history of these judgments. The study demonstrates that the STF "defensive jurisprudence" on the subject is based on a confusion between politics and principle. The study indicates how the Supreme Court's position impacted on the CNJ's authority at the disciplinary and governance levels as well.

Key-words: National Justice Council. Brazilian Supreme Court. Consttutional Procedure. Integrity of law

Sumário: 1. Introdução; 2. A cadeia de decisões sobre a competência originária do STF; 3. Os efeitos da ausência de Integridade judicial; 4. Considerações Finais; 6. Referências.

\section{INTRODUÇÃO}

A relação entre o Supremo Tribunal Federal-STF e o Conselho Nacional de Justiça-CNJ se realiza em duas frentes: administrativamente, pelo exercício da presidência e da vice-presidência, e em nível jurisdicional, pela competência do primeiro em processar e julgar originariamente as ações contra o segundo ${ }^{3}$.

A hierarquia entre os dois órgãos deriva da opção pela modalidade interna de controle da atividade jurisdicional, caminho considerado menos arriscado pelo Supremo Tribunal Federal (FALCÃO, 2010, s/p). Pelo desenho constitucional, os poderes de governança do CNJ não alcançam o STF, porém são desenhados sob o olhar ativo do mesmo, pela presença vigilante do presidente.

Internamente, as atribuições se dividem entre presidência, corregedoria nacional de justiça, conselheiros e plenário ${ }^{4}$. A principal força deveria ser $\mathrm{o}$ colegiado, no entanto, é a presidência, ou seja, o Supremo Tribunal Federal quem

\footnotetext{
3 Art. 102. Compete ao Supremo Tribunal Federal, precipuamente, a guarda da Constituição, cabendo-lhe: I - processar e julgar, originariamente: (...) r) as ações contra o Conselho Nacional de Justiça e contra o Conselho Nacional do Ministério Público;"

${ }^{4}$ Conselho Nacional de Justiça. Resolução 67, de 3 de março de 2009.
} 
conduz o órgão. Além disso, segundo (DOMINGUES COSTA, 2018, s/p), isso se deve aos seguintes fatores: competência para indicar dois conselheiros, responsabilidade pela execução das ações do órgão e definição da pauta de julgamentos.

O regime "presidencialista" como forma de governança no CNJ já foi identificado pela literatura (SADEK 2016, MENDES 2015, MURTA 2018, COSTA 2018). A concentração de poderes em um órgão singular tem impactos graves em todos os tribunais. No caso em análise, como a presidência tem duas cadeiras, a pessoa que a ocupa concentra poderes em dobro.

Embora a crítica presidencialista refira-se ao nível de direção, é relativamente simples identificar que essa forma de governança é reveladora da compreensão do juiz a respeito de seus próprios poderes.

No caso da relação entre o STF e o CNJ, seria esperado que o tribunal concentrasse os poderes quanto ao $\mathrm{CNJ}$, o que não aconteceu, conforme será exposto na primeira seção desse texto. A segunda seção tenta responder porque o STF abriu mão de parte de sua competência originária em relação a um órgão com potencialidade de tomar decisões de grande importância para o poder judiciário. Nesse ponto, demonstra-se também o impacto dessa jurisprudência para o funcionamento do órgão, com foco no poder correcional e na política de governança judiciária.

\section{A CADEIA DE DECISÕES SOBRE A COMPETÊNCIA ORIGINÁRIA DO STF}

Na obra "O Império do Direito", Ronald Dworkin mobiliza várias metáforas para construir sua tese do direito como integridade. A própria ideia de integridade transporta para uma comunidade política um conceito sobre o conteúdo de posições morais individuais. Quando o autor se dispõe a pensar sobre o peso que as decisões 
passadas ou que a história do direito de uma comunidade política deve ter no momento da decisão de um novo caso, Dworkin cria um "gênero literário artificial" chamado romance em cadeia.

De forma simplificada, o dispositivo compara a posição de um juiz com a de um romancista que deve escrever um novo capítulo em uma obra coletiva já iniciada. Quem escreve uma nova decisão ou um novo capítulo tem que se preocupar com a dimensão de adequação, de ajuste ao passado, e uma dimensão de aprimoramento, na qual o dever é fazer daquele texto o melhor possível (DWORKIN, 2003, s/p).

Esse "gênero literário" é útil nesse caso, na medida em que a análise da cadeia de decisões pode esclarecer quais são as razões que sustentam a permanência de um entendimento sobre o papel do STF em relação ao CNJ que deixa o romance incoerente e sem ajuste à Constituição.

Essa história começa com a extensão da competência recursal do STF pela criação do Conselho Nacional de Justiça pela Emenda Constitucional 45/2005. Logo nos primeiros anos, o tribunal criou filtros para reduzir sua participação como instância revisora de todos os atos do CNJ.

O primeiro capítulo desse romance foi escrito em $2006^{5}$, no Mandado de Segurança 26.710/DF, oportunidade em que o STF definiu que não apreciaria ações cujo objeto seria uma deliberação negativa do CNJ. Em outras palavras, quando o julgamento realizado pelo $\mathrm{CNJ}$ não tinha efeito modificativo das posições jurídicas contidas no objeto da apreciação administrativa dos tribunais, a competência para análise da legalidade caberia à jurisdição ordinária ${ }^{6}$.

\footnotetext{
${ }^{5}$ Essa jurisprudência teve início no julgamento da questão de ordem no Mandado de Segurança 26.710/DF, Rel. Min. Dias Toffoli, DJe-173 Publicado 09/09/2011, quando a Corte, em julgamento conjunto com o MS 26.749/DF, acolheu a tese sustentada pelo ministro Sepúlveda Pertence "no sentido de se proceder a uma redução teleológica da alínea "r", do inciso I, do artigo 102, da Constituição da República, para que o STF não se convertesse, por meio de mandado de segurança, em instância ordinária de revisão de todas as decisões do CNJ" .

${ }^{6}$ A propósito, confiram-se os seguintes precedentes: "DIREITO ADMINISTRATIVO. AGRAVO
} 
A decisão foi compreendida como sinal do desenvolvimento de uma "jurisprudência defensiva" no que tange ao CNJ (COSTA, PENALVA, 2015, s/p). Vale notar que o mencionado posicionamento se dá logo após a criação do CNJ e das alterações que a Emenda Constitucional 45/2004 trouxe ao processo civil. Nesse momento, as estratégias de bloqueio à jurisdição dos tribunais superiores e a crítica à criação de barreiras que impediam muitas vezes a apreciação de questões constitucionais dominava a doutrina processual.

Como anota (TORRE, 2015, s/p), um dos objetivos dessa jurisprudência era "a redução excessiva da carga de trabalho das cortes superiores". Embora a crítica doutrinária se dirigisse aos entraves à admissibilidade dos recursos extraordinários, o móvel parece o mesmo em relação à competência originária disposta no art. 102-Ir da Constituição Federal de 1988.

A inconsistência mais evidente desse entendimento, e que não demorou a aparecer, foi quanto aos efeitos das decisões do $\mathrm{CNJ}$, no que se refere a partes e interessados. Conforme aponta (COSTA, PENALVA, 2019, s/p), "há casos em que a mesma decisão do CNJ tem efeitos positivos e negativos, ou seja, enseja a competência revisional do Supremo Tribunal Federal e das instâncias ordinárias".

Em termos de princípio, o entendimento falha porque compreende mal a posição do Conselho Nacional de Justiça na estrutura do Poder Judiciário. A apreciação pelo STF de ações judiciais contra o órgão não é apenas um regra de competência, é reforço do princípio hierárquico que propicia ao CNJ exercer sua função correcional e desenhar a política de governança do poder judiciário, tarefas para as quais foi criado.

REGIMENTAL EM MANDADO DE SEGURANÇA. REVISÃO DISCIPLINAR. DECISÃO NEGATIVA DO CNJ. INCOMPETÊNCIA ORIGINÁRIA DO STF. IMPOSIÇÃO DE MULTA. 1. Não compete ao STF julgar, em caráter originário, as ações que impugnem decisões negativas do $\mathrm{CNJ}$, i.e., aquelas que, mantendo ato proferido por outro órgão, não agravam a situação dos interessados. Precedentes. 2. Agravo regimental a que se nega provimento, com aplicação de multa de 5\% (cinco por cento) do valor corrigido da causa, ficando a interposição de qualquer outro recurso condicionada ao depósito do respectivo valor". ( BRASIL, STF, 2016) 
O segundo capítulo nesse processo de restrição de acesso à jurisdição competente foi escrito na Ação Originária $n^{0}$ 1.706-AgR/DF (BRASIL, STF, 2014a), em que o STF definiu que apreciaria apenas algumas classes de ações contra o CNJ. A competência estaria adstrita às ações de cunho mandamental: mandado de segurança, mandado de injunção, habeas data e habeas corpus. É certo, como apontou o relator Ministro Celso de Mello, que o CNJ integra a União, por isso, só figuraria como parte quando apontado como órgão coator. Ocorre que essa condição é artificial, na medida em que não há diferenças em termos materiais entre os conteúdos que podem ser articulados por ações ordinárias ou mandamentais.

Novamente, a regra processual superou o princípio constitucional, consequentemente, penalidades administrativas impostas pelo $\mathrm{CNJ}$, resoluções que desenhem políticas judiciárias e quaisquer outras decisões quando questionadas em ação ordinária passaram a ser julgadas pelos juízes de primeira instância. O objeto do controle (juízes e tribunais) passa a ter competência para rever os atos daquele que o controla.

A inversão de importância entre interesse (redução de carga de trabalho), regra (procedimento) e princípio (hierarquia e controle) não parece difícil de ser identificada. Em uma das passagens do segundo capítulo dessa cadeia de decisões, na AO n 1.814/MG e ACO n 1.680/AL, de 24/09/2014 (BRASIL, STF, 2014b), o Ministro Dias Toffoli adotou um novo ponto de vista, uma leitura melhor do projeto constitucional que desenhou uma nova instituição para o poder judiciário. $\mathrm{O}$ Ministro percebeu que a competência do STF existe como "mecanismo assecuratório da própria finalidade do $\mathrm{CNJ}$ e da imperatividade de suas decisões, em face dos órgãos e dos membros submetidos à sua autoridade”. As seguintes materiais deveriam ser julgadas pelo STF: 
que desconstituam ato normativo ou deliberação de tribunal local relacionados a matérias a esse diretamente afetas (como foi o caso da Rcl $\mathrm{n}^{\circ}$ 15.551/GO); e (iii) outras em que a atuação do CNJ se dê, precipuamente, na consecução de sua atividade fim, quando direta e especialmente incidente sobre membros e órgãos a ele diretamente subordinados (TOFFOLI, 2015, p. 79-100).

O novo capítulo que o Ministro Toffoli tentou escrever não seria suficiente para reintegrar o sistema, já que a competência ainda estaria fragmentada. Porém, os fundamentos de sua posição eram melhores já que articulavam os riscos da decisão para a autoridade do CNJ e para a própria normatividade da Constituição. Essa posição, entretanto, não prevaleceu, embora tenha sido articulada em alguns casos julgados pela Segunda Turma do $\mathrm{STF}^{7}$.

\section{OS EFEITOS DA AUSÊNCIA DE INTEGRIDADE JUDICIAL}

A integridade é um ideal político que exige dos aplicadores do direito o enfrentamento dos problemas e desafios jurídicos como uma questão de princípio. A integridade indica ao julgador que, quando escolher a direção que tomará em uma decisão, o faça não como algo passageiro que apresente uma posição atraente apenas no caso presente, mas que o faça ciente de que está se posicionando quanto a uma concepção mais ampla do direito (DWORKIN, p. 308).

No caso em análise, a compreensão de que qualquer decisão é reveladora de concepções mais ampla sobre o direito é de extrema utilidade, porque incorpora a cada julgamento o impacto que terá na cadeia de decisões que compõe um sistema jurídico.

Em 2016, o plenário do Conselho Nacional de Justiça determinou a aposentadoria compulsória de juiz de direito do Estado de Roraima, no

\footnotetext{
7 BRASIL, STF, 2017a; BRASIL, STF, 2015a; BRASIL, STF, 2017b; BRASIL, STF, 2015b; BRASIL, STF, 2014.
} 
procedimento de Revisão Disciplinar n. 0006295-97.2011.2.0000 ${ }^{8}$. O juiz acionou o Supremo Tribunal Federal por via do Mandado de Segurança 33.565/DF${ }^{9}$, Relatora Ministra Rosa Weber. A segurança foi denegada por unanimidade.

Porém, mesmo após longo voto em que se reconheceu que a penalidade foi imposta a partir de "juízo formado pela maioria dos membros do CNJ, à luz do princípio do livre convencimento motivado e das provas coligidas aos autos do processo de revisão disciplinar", a Ministra indicou que a inexistência de prova suficiente para atender os requisitos da ação mandamental "não impede que o impetrante lance mão das vias ordinárias para defesa do seu alegado direito.”

O impetrante então propôs ação ordinária perante a $5^{\text {a }}$ Vara da Seção Judiciária do Distrito Federal e obteve a concessão de tutela antecipada para sua reintegração ao cargo. Contra essa decisão, a Advocacia-Geral da União ajuizou Reclamação no Supremo Tribunal Federal.

A Reclamação 35.168 / DF foi distribuída ao Ministro Marco Aurélio que, em 04/06/2019, lhe negou seguimento. A razão apontada pelo Ministro foi o julgamento pelo Plenário do STF, na sessão ocorrida em 24 de setembro de 2014,

8 TRIBUNAL DE JUSTIÇA DO ESTADO [...]. REVISÃO DISCIPLINAR. MAGISTRADO. PROVAS INEQUÍVOCAS DE "VENDA" DE SENTENÇA.1. Imputação de recebimento de vantagem econômica para proferir decisão favorável a uma das partes de recurso de Agravo de Instrumento. 2. Necessidade de revisão da decisão originária em face de conjunto probatório que evidencia a infração dos deveres previstos no art. 35, I e VIII, da LOMAN, com a prática de conduta incompatível com a dignidade, a honra e o decoro de suas funções jurisdicionais. 3. A conduta comprovada do Requerido de receber vantagem indevida em troca de decisão judicial ostenta a mais extrema gravidade que o estatuto disciplinar da magistratura pode prever, o que justifica a aplicação da sanção administrativa de aposentadoria compulsória com vencimentos proporcionais ao tempo de serviço. 4. Remessa dos autos à Procuradoria-Geral da República para conhecimento. (CNJ, 2015)

9 MANDADO DE SEGURANÇA. ATO DO CONSELHO NACIONAL DE JUSTIÇA QUE APLICOU A PENA DE APOSENTADORIA COMPULSÓRIA AO IMPETRANTE. EXERCÍCIO DE ATRIBUIÇÃO PREVISTA NO ART. 103-B, $\S 4^{\circ}, \mathrm{V}$, DA CARTA MAGNA. INDEPENDÊNCIA DAS ESFERAS PENAL E ADMINISTRATIVA. HIPÓTESE DE COMUNICABILIDADE NÃO CONFIGURADA. SUSTENTADA INAPTIDÃO DAS PROVAS COLIGIDAS AO PROCESSO DE REVISÃO DISCIPLINAR PARA FUNDAMENTAR O ATO IMPUGNADO. SITUAÇÃO DE CONTROVÉRSIA OBJETIVA. ILIQUIDEZ DOS FATOS QUE DÃO SUPORTE À IMPETRAÇÃO. SEGURANÇA DENEGADA. (BRASIL, STF, 2016) 
que ao dirimir a questão de ordem na Ação Originária $\mathrm{n}^{\circ} 1.814$, assentou que a competência do STF para apreciar ações contra o Conselho Nacional de Justiça e o Conselho Nacional do Ministério Público, versada no artigo 102, inciso I, alínea "r", da Constituição Federal, abrange somente as ações de cunho mandamental. A decisão proferida na Reclamação foi desafiada por recurso de agravo, até a esta data, ainda não julgado pela $1^{\text {a }}$ Turma.

O que poderia em princípio parecer uma acomodação da jurisprudência do STF demonstra sim um agravamento da situação de insegurança gerada, desta feita, pelo reconhecimento de múltiplas oportunidades para o ataque às decisões do CNJ. No caso em análise, em que a discussão girou em torno da conduta funcional de um juiz, matéria correcional, não só o STF reafirmou sua jurisprudência defensiva pela decisão monocrática proferida na Reclamação, como sugeriu a possibilidade de sobreposição de instâncias, ainda quando da denegação da ordem no Mandado de Segurança.

Vale lembrar que o próprio STF já reconheceu a importância da competência concorrente do $\mathrm{CNJ}$ e dos tribunais nas ações de natureza correcional. No julgamento da medida cautelar na ADI 4.638 MC-REF/ DF (BRASIL, STF, 2012), em que se discutiu a constitucionalidade da Resolução CNJ 135/2011 que define os procedimentos disciplinares, indicou o Ministro Gilmar Mendes que: “Até as pedras sabem que as corregedorias não funcionam quando se cuida de investigar os próprios pares".

$\mathrm{O}$ próprio $\mathrm{CNJ}$ já esboçou alguma reação ao esvaziamento de sua função correcional nas Recomendações 38 e 39, de 19 de junho de 2019, da Corregedoria Nacional de Justiça. A Recomendação 38/2019 indica a todos os tribunais que "dêem cumprimento aos atos normativos e às decisões proferidas pela Corregedoria Nacional de Justiça, ainda que exista ordem judicial em sentido diverso, salvo se advinda do Supremo Tribunal Federal.” A segunda recomenda aos Tribunais que deem cumprimento ao Provimento 77 e às decisões proferidas pela Corregedoria 
Nacional de Justiça, que coíbem a prática de nepotismo, ainda que haja decisão judicial em sentido diverso mantendo no cargo interinos parentes de antigos delegatários titulares das serventias vagas, salvo se a ordem judicial advier do Supremo Tribunal Federal. Ambas as normas foram suspensas liminarmente pelo Ministro Marco Aurélio nos Mandados de Segurança 36.549/DF e MS 36.550/DF ${ }^{10}$, menos de dez dias após sua edição.

Os impactos dessa jurisprudência também foram sentidos na política de governança. A ação ordinária, procedimento comum $\mathrm{n}^{\circ}$ 502562906.2019.4.04.7200/SC ${ }^{11}$ foi proposta perante o juízo Federal da $4^{\mathrm{a}}$ Vara de Florianópolis, pela Procuradoria do Estado de Santa Catariana, com pedido de antecipação de tutela. ${ }^{12} \mathrm{O}$ caso tem imensa relevância para as atividades de governança desempenhadas pelo CNJ. Trata-se de conflito a respeito da adoção pelos tribunais de um processo judicial único, política de grande investimento e com grande potencial de melhorias no acesso à justiça.

Essa talvez seja a política judiciaria mais controvertida do CNJ, por seus impactos orçamentários e políticos. No caso, o TJSC pretendia suspender a obrigação imposta pelo Conselho de migração de seus sistemas processuais para o Processo Judicial Eletrônico. O juiz federal, em 04 de novembro último deferiu a

11 Vale recuperar os pedidos expostos na inicial e que esclarecem a inversão de poderes que a jurisprudência defensiva criou: "a) possibilitar ao Tribunal de Justiça do Estado de Santa Catarina a manutenção do uso do já implantado sistema eproc como seu sistema de processo eletrônico e interoperacional, ante a expressa previsão contida nos arts. $8^{\circ}$ e 14 da lei n. 11.419/06, bem como para que seja desobrigado a implementar o sistema SEEU, ante a existência de sistema já em funcionamento com a necessária interoperabilidade; b) determinar ao Conselho Nacional de Justiça que se abstenha de suspender, impedir ou criar qualquer embaraço, seja de ordem técnica, operacional, procedimental ou financeira, bem como de aplicar penalidade ao TJSC, seus dirigentes e servidores/colaboradores, decorrentes direta ou indiretamente, do pleno funcionamento do eproc e suas futuras atualizações, no Poder Judiciário de Santa Catarina, inclusive no que respeita ao Sistema Eletrônico de Execuções Penais -SEEU; E, por fim que: "após o devido processamento, seja declarada a legalidade e o direito do Autor permanecer na utilização do sistema eproc, bem como seja declarada a desobrigação de implantação e adoção do denominado sistema SEEU, ante a existência de sistema interoperável (eproc), com semelhantes e superiores funcionalidades, já em pleno funcionamento." 
medida de urgência. O que, na prática, obsta a política estruturante do CNJ no que se refere a utilização do PJe em todo o território Nacional, nos termos da Resolução 185, de 18 de dezembro de 2013.

Vale lembrar, todavia, que ainda em 2017, o STF começava a rascunhar o terceiro capítulo desse romance. No Agravo Regimental na Petição 4.656 (STF, 2017, s/p), a relatora Ministra Cármen Lúcia, ao avaliar a competência do STF em relação a atos do CNJ, já apontava:

[...] a restrição do permissivo constitucional da al. $\mathrm{r}$ do inc. I do art. 102 da Constituição da República às ações de natureza mandamental resultaria em conferir à Justiça federal de primeira instância, na espécie vertente, a possibilidade de definir os poderes atribuídos ao Conselho Nacional de Justiça no cumprimento de sua missão, subvertendo, assim, a relação hierárquica constitucionalmente estabelecida.

A escrita desse capítulo continua em 2019, na Reclamação 15.564/PR (BRASIL, STF, 2019) em que a redator para o acórdão Ministro Luiz Fux reconhece o equívoco do tribunal ao eleger a natureza processual da demanda para avaliar se o caso mobilizaria a competência originária disposta no art. 102-I- "r" da Constituição de 1988. Em suas palavras:

A dispersão das ações ordinárias contra atos do CNJ nos juízos federais de primeira instância tem o condão de subverter a posição que foi constitucionalmente outorgada ao Conselho, fragilizando sua autoridade institucional e a própria efetividade de sua missão. Decerto, a submissão de atos e deliberações do CNJ à jurisdição de membros e órgãos subordinados a sua atividade fiscalizatória espelha um indesejável conflito no sistema e uma dilapidação de seu status hierárquico no sistema constitucional.

A "jurisprudência defensiva" não foi integralmente abandonada, no entanto. Está explícita na decisão a preocupação com a "capacidade decisória do tribunal", 
sua funcionalidade e os riscos de eventual banalização ${ }^{13}$. Ao insistir em fragmentar a competência revisional, o STF perde mais uma chance de reafirmar sua autoridade jurisdicional quanto ao $\mathrm{CNJ}$.

O novo capítulo que se delineia reinterpreta o dispositivo constitucional e fixa como competência do tribunal as ações: (a) de caráter normativo ou regulamentar que definem as políticas nacionais, (b) que desconstituam ato normativo de tribunal local, (c) que envolvam interesse direto e exclusivo de todos os membros do Poder Judiciário, e (d) que versem sobre serventias judiciais e extrajudiciais. As demais ações contra o $\mathrm{CNJ}$ continuam sendo de competência do primeiro grau.

Embora o julgado melhore substancialmente o romance, ele perde a chance de deixa-lo sob a melhor luz. Não há razão de princípio que justifique esse caminho interpretativo. As ações contra o CNJ não são as que ameaçam a funcionalidade do STF. Não são esses os processos que podem impactar a efetividade do direito fundamental de acesso à justiça.

O efeito, na verdade, é o oposto. É o CNJ quem vem definindo estratégias de governança com potencial de aprimoramento do sistema de justiça brasileiro. Do ponto de vista processual, também não há princípios que justifiquem a interpretação restritiva. Esse terceiro capítulo em desenvolvimento parece optar pela via conciliatória, na qual são feitas concessões internas, algo que o ideal da integridade rejeita com vigor exatamente porque não se firma em princípios.

\section{CONSIDERAÇÕES FINAIS}

A recuperação do histórico de decisões do Supremo Tribunal Federal a respeito da norma contida no art. 102-I- "r" da Constituição Federal revelou a

${ }^{13} \mathrm{O}$ Ministro Alexandre de Moraes menciona diretamente a jurisprudência defensiva em seu voto. 
ausência de integridade do Supremo Tribunal Federal ao julgar as ações judiciais contra o Conselho Nacional de Justiça. O ideal da integridade informa que as autoridades têm responsabilidades coletivas antes mesmo de sua responsabilidade específica, ou seja, o compromisso do STF com sua carga de trabalho não pode prevalecer em face de sua responsabilidade como agente de respaldo da correção das ações do CNJ.

A consequência de capítulos incoerentes e confusos foi a desordem e instabilidade dos poderes de governança e de exercício do poder disciplinar pelo CNJ. Os próprios juízos de primeiro grau que, por um lado, ganharam novos poderes também ficaram em posição de constrangimento. Embora não haja hierarquia funcional e que juízes de primeiro grau possam julgar, por exemplo, atos cometidos por desembargadores, o contexto de decisões administrativas e de governança judiciária torna o cenário mais complexo.

$\mathrm{O}$ argumento da "jurisprudência defensiva", oferecido pelo STF como fundamento para sua posição no tema, é razão de utilidade, é argumento de política e não de direito. A gestão de processos judiciais, a administração das demandas e das formas de eficiência na prestação jurisdicional não podem rivalizar com princípios jurídicos. A efetividade da norma constitucional que cria o Conselho Nacional de Justiça depende do sistema na qual foi inserida. A força mandatória do órgão é assegurada pela jurisdição do STF, de forma que seu esvaziamento impacta diretamente a autoridade do último. Afinal, por que os tribunais se submeteriam a um tipo de controle e supervisão que, regra geral, lhes impõe novas obrigações e restrições?

É dever do STF reconhecer um "propósito ao texto" constitucional mesmo quando o melhor propósito não seja "plenamente bem-sucedido" ou quando traga consigo consequências não planejadas. Propósito a ser identificado não como intenção do constituinte recuperada pelo método histórico, mas como dimensão normativa do texto (DWORKIN, 2010). 
O STF, como um dos escritores do romance, deve observar a si próprio para manter a integridade da narrativa, para assegurar que personagens não desapareçam ou se tornem secundários antes de cumprir seu papel no enredo. Para que o sistema de justiça possa ser dirigido, monitorado e avaliado, nos termos da Constituição, é indispensável que seja tomado como tal, ou seja, como um conjunto de unidades que se organizam racional e normativamente.

\section{REFERÊNCIAS}

DWORKIN, Ronald. Império do Direito. $1^{\text {a }}$ ed. São Paulo: Martins Fontes, 2003.

FALCÃO, Joaquim. A história da reforma do Poder Judiciário e de sua estratégia pré-legislativa. In: Dez anos de reforma do judiciário e o nascimento do Conselho Nacional de Justiça. STOCO, Riu. PENALVA, São Paulo: Editora Revista dos Tribunais, 2015.

TORRE, Riccardo. A valorização dos precedentes pelos tribunais superiores e a jurisprudência defensiva. Dissertação de Mestrado. Faculdade de Direito da Universidade de São Paulo. Universidade de São Paulo, São Paulo, 2015.

COSTA, Adriene Domingues. A Política Judiciária do CNJ e seus Impactos Institucionais. O CNJ e a Efetivação da Justiça. Organizador Claudio Lamachia, Oneildo Ferreira, Valdetário Andrade Monteiro - Brasília, OAB, Conselho Federal, 2019. P. 25-47.

MURTA, João. Análise das Iniciativas Implementadas pelo Conselho Nacional de Justiça no Sistema de Execução Penal. Dissertação Mestrado. IDP. Disponível em https://www.conjur.com.br/dl/pesquisador-aponta-descontinuidade.pdf

PENALVA, Janaína. Costa, Adriene Domingues. Dez anos depois: quem julga os atos do Conselho Nacional de Justiça? Revista do Advogado, v. Ano XXXV, p. 38, 2015.

SADEK, M. T.. CNJ: impactos no Judiciário e na sociedade. In: STOCO, Rui; PENALVA, Janaína. (Org.). Dez Anos de Reforma do Judiciário e o nascimento do Conselho Nacional de Justiça. 1. ed.São Paulo: Editora Revista dos Tribunais, 2015, v. 1, p. 293-312. 
TOFFOLI, José Antônio Dias. A competência do Supremo Tribunal Federal para julgar ações em que se impugnam decisões do Conselho Nacional de Justiça. In: LEWANDOWSKI, Ricardo; NALINI, José Renato (Org.). O Conselho Nacional de Justiça e sua atuação como órgão do Poder Judiciário: homenagem aos 10 anos do CNJ. São Paulo: Quartier Latin, 2015, p. 79-100.

Data da submissão: 25/11/2019

Data da primeira avaliação: 29/11/2019 Data da segunda avaliação 20/12/2019

Data da aprovação: 20/12/2019 